\title{
Rescue of Motor Coordination by Purkinje Cell-Targeted Restoration of Kv3.3 Channels in Kcnc3-Null Mice Requires Kcnc1
}

\author{
Edward C. Hurlock, Mitali Bose, Ganon Pierce, and Rolf H. Joho \\ Department of Neuroscience, The University of Texas Southwestern Medical Center, Dallas, Texas 75390-9111
}

The role of cerebellar Kv3.1 and Kv3.3 channels in motor coordination was examined with an emphasis on the deep cerebellar nuclei (DCN). Kv3 channel subunits encoded by Kcnc genes are distinguished by rapid activation and deactivation kinetics that support high-frequency, narrow action potential firing. Previously we reported that increased lateral deviation while ambulating and slips while traversing a narrow beam of ataxic Kcnc3-null mice were corrected by restoration of Kv3.3 channels specifically to Purkinje cells, whereas $K c n c 3$-mutant mice additionally lacking one $K c n c 1$ allele were partially rescued. Here, we report mice lacking all $K c n c 1$ and $K c n c 3$ alleles exhibit no such rescue. For Purkinje cell output to reach the rest of the brain it must be conveyed by neurons of the DCN or vestibular nuclei. As Kcnc1, but not Kcnc3, alleles are lost, mutant mice exhibit increasing gait ataxia accompanied by spike broadening and deceleration in DCN neurons, suggesting the facet of coordination rescued by Purkinje-cell-restricted Kv3.3 restoration in mice lacking just $K c n c 3$ is hypermetria, while gait ataxia emerges when additionally $K c n c 1$ alleles are lost. Thus, fast repolarization in Purkinje cells appears important for normal movement velocity, whereas DCN neurons are a prime candidate locus where fast repolarization is necessary for normal gait patterning.

\section{Introduction}

An intriguing subpopulation of neurons displays the ability to sustain spiking at high rates in excess of $\sim 200 \mathrm{~Hz}$ (Chow et al., 1999; Henderson et al., 2004; Bartos et al., 2007; Chesselet et al., 2007). To date, voltage-gated potassium channels $(\mathrm{Kv})$ of the Kv3 subfamily are invariably present and necessary for maximal firing rates in these fast-spiking neurons (Lau et al., 2000; Matsukawa et al., 2003; McMahon et al., 2004; Song et al., 2005; Kasten et al., 2007; Espinosa et al., 2008). Kv3 channels are distinguished by rapid activation and deactivation, which confer upon them the ability to rapidly repolarize action potentials. By activating quickly, they maintain action potential brevity and, by deactivating quickly, allow for spiking at high rates. Four separate genes (Kcncl-4) encoding subunits Kv3.1Kv3.4 assemble into homotetrameric and heterotetrameric channels, exhibiting distinctive and overlapping expression patterns (Rudy et al., 1999; Rudy and McBain, 2001).

In the cerebellar cortex (Fig. 1), the projection neurons, Purkinje cells, express Kv3.3 throughout the cell and Kv3.4 largely in dendrites (Martina et al., 2003; McMahon et al., 2004; Chang et al., 2007). Granule cells express Kv3.1 and Kv3.3 (Weiser et al., 1995; Sekirnjak et al., 1997; Ozaita et al., 2002), whereas basket cells express Kv3.2 and Kv3.4 channel subunits in the pinceaux (Veh et al., 1995; Bobik et al., 2004). In the deep cerebellar nuclei

\footnotetext{
Received Aug. 18, 2009; revised 0ct. 6, 2009; accepted 0ct. 7, 2009.

This study was supported in part by National Institutes of Health Grant NS042210 to R.H.J. We thank Dr. Jay Gibson for a critical reading of this manuscript.

Correspondence should be addressed to Rolf H. Jolo at the above address. E-mail: Rolf.Joho@ utsouthwestern.edu.

D01:10.1523/JNEUROSCI.4048-09.2009

Copyright $\odot 2009$ Society for Neuroscience ～0270-6474/09/2915735-10\$15.00/0
}

(DCN) and analogous vestibular nuclei, mRNA for all subfamily members is present (Weiser et al., 1994), with Kv3.1 and Kv3.3 protein is expressed in large, presumably glutamatergic projection neurons (Weiser et al., 1995; McMahon et al., 2004). Kv3.2 protein is also present in these nuclei (Lau et al., 2000), and Kv3.4 has not been examined here.

Mice expressing $K c n c 1$ but lacking $K c n c 3(+/+;-/-)$ exhibit ataxia and abnormal spiking in Purkinje cells which rely on Kv3.3 for brief action potentials (McMahon et al., 2004). Re-expression of Kv3.3 selectively in Purkinje cells restored spike parameters and rescued motor coordination in $+/+;-/-$ mice as well as in mice additionally lacking one Kcncl allele $(+/-;-/-)$ (Hurlock et al., 2008). As Purkinje cell firing is potentially related to the control of fine motor timing or speed, determination of what aspect of motor function was affected in the ataxia of $+/+;-/-$ mutants is of interest.

For electrophysiological alterations to be consequential for behavior, the intrinsic firing properties of DCN neurons must be reasonably intact for the rescue of fast repolarization in Purkinje cells to be efficacious in averting ataxia in $+/+;-/-$ mutants (Fig. 1). Large, non-GABAergic DCN projection neurons express Kv3.1 and Kv3.3 channel subunits. Thus, we assessed Kcnc1/ Kcnc3 double-knock-out (-/-; -/ - ) mice for a behavioral and electrophysiological rescue. To extricate whether the ataxia stems from hypermetric speed/force, timing of limb movement, or relative timing across limbs, we also measured high-speed motor performance and gait pattern alterations. To define which electrophysiological changes could most plausibly account for the ataxia, we examined intrinsic spiking of DCN neurons in mice lacking Kcnc3 as well as Kcnc1 alleles. 


\section{Materials and Methods}

\section{Mouse breeding}

The generation and initial characterization of mice lacking Kv3.1 and $\mathrm{Kv} 3.3 \mathrm{~K}^{+}$channels has been described previously (Ho et al., 1997; Espinosa et al., 2001, 2004; Joho et al., 2006), as has the generation of mutant mice with Kv3.3b restored selectively to Purkinje cells (Hurlock et al., 2008). To avert genetic drift, no separate wild-type or mutant colonies were established, and to equalize the unavoidable genetic variability among individual mice of different genotypes, extended brother-sister mating was avoided. Using this breeding scheme, the genetic background varied among individual mice; however, the extents of variability were similar among mice of different genotypes. Mice were kept on $11 \%$ fat chow (Harlan) from weaning onwards to reduce mortality of $-1-$; $-/-$ mice and better equalize body size to that of wild-type controls. All experiments were approved by the Institutional Animal Care and Research Advisory Committee.

\section{Behavior}

For behavioral tests, naive mice were first tested once on the force-plate actometer followed by the beam test on 5 consecutive days. Males and females were used because we did not observe gender differences in these tests (Joho et al., 2006). Mice were kept on a $12 \mathrm{~h}$ light/dark cycle, and all behavioral experi-

ments were performed with age-matched mice ( $\sim 3-6$ months of age) unless otherwise specified.

Measurement of lateral deviation. Individual, naive mice were allowed to freely explore a platform $(28 \times 28 \mathrm{~cm})$ for 6 min resting on four force transducers. The walking trajectory during epochs of linear ambulation on the plate is represented by connections of temporally consecutive centers of force (COFs), which are approximately the center of gravity determined by which paws are on the plate, how far paw placements are from each other, and how much force is applied during stepping. The total distance traveled is the sum of the linear distances ( $\Sigma$ di) between consecutive COFs. The area measure corresponds to the sum of all triangular areas ( $\Sigma$ ai) defined by every three consecutive COF measurements (Fowler et al., 2001; Joho et al., 2006). For a quantitative measure of lateral deviation from the main walking trajectory, the summed areas ( aai) generated during the 6 min test are divided by the total distance traveled $(\Sigma$ di $)$ to obtain the lateral deviation index $(\mathrm{LDI}=\Sigma \mathrm{ai} / \Sigma \mathrm{di})$. The LDI would equal zero if the walking trajectory were a straight line (area measure equals zero). The LDI (in millimeters) increases with increasing lateral deviation of the COFs from the main trajectory of movement.

Beam test. The beam test was performed as described previously (Joho et al., 2006). Mice were placed at the end of a $100-\mathrm{cm}$-long, 2-cm-wide Plexiglas beam suspended $10 \mathrm{~cm}$ above a surface and allowed to traverse the beam five times per day (no interval between trials) on 5 consecutive days. Sideways falls (loss of balance) on the $2 \mathrm{~cm}$ beam were counted by an observer blind to genotype. The average numbers of sideways falls per $100 \mathrm{~cm}$ traveled and the fraction of mice able to perform were used for data presentation and analysis. After a fall, mice were placed back on the beam where the fall had occurred and released once they regained their footing. When $-/-;-/-$ mice had fallen 15 times, they were deemed unable to perform.

DigiGait analysis. Mice used on the DigiGait treadmill largely overlapped those used in the study by Hurlock et al. (2008). For the $+/+$; $-/-$ breakpoint speed experiments, mice were 10-12 months old with an even sex ratio. These mice were placed on the belt that was accelerated as described below for gait analysis until mice could no longer sustain the speed. For gait analysis we used male $+/-;-/-$ mice because their ataxia is more severe than mice lacking Kcnc3 alone, yet $+/-;-/-$ mice are still capable of running on the treadmill. Thus, if a deficit had been present in $+/+;-/-$ mice it should also have been evident in $+/-;-1-$ mice. Mice heterozygous for Kcnc3 $(+/+;+/-)$ used as normal controls were found previously to have wild-type levels of lateral deviation and beam slips. Data were acquired by first painting the paws of mice with a red and extraneous reddish parts of the mice with a blue Betty Crocker Easy Writer cake-decorating marker and placing the mice on the stationary DigiGait treadmill (Mouse Specifics). Paws were detected as red color contacting the belt and blue was ignored. The treadmill was equipped with a Plexiglas chamber mounted over the area monitored by the camera to keep the mouse running in place and in view. The ceiling was dropped with clear tape to prevent rearing. The belt was turned on at an initial speed of $5-10 \mathrm{~cm} / \mathrm{s}$. The speed was increased in increments of 5 $\mathrm{cm} / \mathrm{s}$, and each stepwise increase lasted for $\sim 5 \mathrm{~s}$ until the speed was increased again. Recordings for gait analysis were made once the mouse was able to reach $25 \mathrm{~cm} / \mathrm{s}$ consistently to produce 10 suitable consecutive strides uninterrupted by pauses causing backward drifting on the belt.

\section{Immunohistochemistry}

Adult mice anesthetized with avertin were transcardially perfused with cold Dulbecco's PBS [ $1 \times$ DPBS containing the following (in $\mathrm{mM}$ ): 1.5 $\mathrm{KH}_{2} \mathrm{PO}_{4}, 8.1 \mathrm{Na}_{2} \mathrm{HPO}_{4}, 136.9 \mathrm{NaCl}$ and $2.7 \mathrm{KCl}$, $\left.\mathrm{pH} 7.4\right]^{`}$ followed by $4 \%$ paraformaldehyde in $1 \times$ DPBS. Brains were dissected and postfixed for $1 \mathrm{~h}$ at $4^{\circ} \mathrm{C}$, followed by cryoprotection in $40 \%$ sucrose in DPBS at $4^{\circ} \mathrm{C}$. The tissue was embedded in OCT, sectioned at $20 \mu \mathrm{m}$ coronally or sagittally, and stored at $-20^{\circ} \mathrm{C}$ in storage buffer ( $80 \mathrm{~mm}$ DPBS, $30 \%$ glycerol, and $30 \%$ ethylene glycol) until free-floating immunohistochemistry was performed with net wells.

Frozen sections in storage buffer were first given three $10 \mathrm{~min}$ washes in $1 \times$ DPBS followed by a $2-3 \mathrm{~h}$ incubation with blocking solution $(4 \%$ goat serum, $5 \%$ BSA, $0.3 \%$ Triton X-100, 0.05\% Tween 20 in $1 \times$ DPBS). Gentle agitation was used during all incubations. Primary antibodies including rabbit anti-Kv3.3 (1:650; Alomone), mouse anti-Kv3.1b (1:50; Antibodies Inc.), rabbit anti-Kv3.2 (1:500; Alomone), rabbit anti-Kv3.4 (1:200; Alomone), mouse anti-SMI-32 (1:1000; Covance), mouse $\left(\operatorname{IgG}_{2 \mathrm{a}}\right)$ anti-GAD67 (1:2000; Millipore Bioscience Research Reagents), and mouse anti-calbindin (1:750; Swant) were applied overnight in blocking solution at $4^{\circ} \mathrm{C}$ followed by four $10 \mathrm{~min}$ washes in $1 \times$ DPBS 
Goat anti-rabbit Alexa 568-, Alexa 488-, or Alexa 633- or anti-mouse Alexa 568-, Alexa 488-, or Alexa 647-conjugated secondary antibodies (Invitrogen) were applied in blocking solution at 1:400 at room temperature for 3-4 h followed by three $10 \mathrm{~min}$ rinses in $1 \times$ DPBS. Sections were mounted on Probe-On Slides (Fisher) and dried. Slides were dehydrated in graded ethanols and defatted in xylene. Images were collected digitally using a $63 \times$ oil objective on a Zeiss LSM 510 confocal microscope equipped with a krypton/argon mixed-gas laser.

\section{Brain slice preparation and recording}

Mice aged from postnatal day 17 (P17) to P21 were anesthetized with ketamine/acepromazine by intraperitoneal injection before perfusion at $20 \mathrm{ml} / \mathrm{min}$ with $20-30 \mathrm{ml}$ of ice-cold artificial CSF (aCSF) for preparing slices. aCSF for preparing slices contained the following (in $\mathrm{mm}$ ): 228 sucrose, $3.25 \mathrm{KCl}, 0.5 \mathrm{CaCl}_{2}, 7 \mathrm{MgCl}_{2}, 28 \mathrm{NaHCO}_{3}, 7$ D-glucose, $3 \mathrm{Na}$ pyruvate, 1 ascorbic acid; preoxygenated by carbogen $\left(95 \% \mathrm{O}_{2}, 5 \% \mathrm{CO}_{2}\right)$ gas. Ascorbic acid and pyruvate were added fresh from frozen stocks. aCSF contained the following (in $\mathrm{mm}$ ): $125 \mathrm{NaCl}, 3.25 \mathrm{KCl}, 1.5 \mathrm{CaCl}_{2}, 1.5$ $\mathrm{MgCl}_{2}, 25 \mathrm{NaHCO}_{3}, 25$ D-glucose; preoxygenated by carbogen $\left(95 \% \mathrm{O}_{2}\right.$, $5 \% \mathrm{CO}_{2}$ ) gas. Parasagittal, $200-\mu \mathrm{m}$-thick slices principally comprising the medial nucleus were cut from the vermis on a Vibratome (Ted Pella). Recovery proceeded in regular recording aCSF as described previously (Hurlock et al., 2008).

Recording was performed in current-clamp mode using the following (in mM): $130 \mathrm{~K}$-methylsulfonate, 0.1 EGTA, 10 HEPES, $7 \mathrm{NaCl}, 0.3$ $\mathrm{MgCl}_{2}, 5$ di-Tris creatine- $\mathrm{PO}_{4}, 2$ Tris-ATP, and $0.5 \mathrm{Na}-\mathrm{GTP}$, as in the study by Hurlock et al. (2008). Data were filtered at $3 \mathrm{kHz}$ via the amplifier and sampled at $200 \mathrm{kHz}$ to provide adequate resolution of fast spikes for measurement of waveform parameters in Minianalysis (Synaptosoft) with pCLAMP 9.2 software (Molecular Devices). Action potential waveform measurements were taken 4-5 min after breaking into the cell. Recordings were made without current injection to measure the spontaneous spike rate and action potential waveform parameters. Measurements were taken after the spike rate settled to a steady state yet within $2 \mathrm{~s}$ of turning off hyperpolarizing bias current initiated after break-in and otherwise maintained throughout the recording. Normal aCSF was used except $25 \mu \mathrm{M} \mathrm{D}-(-)$ 2-amino-5-phosphonopentanoic acid (D-AP5; Ascent Scientific) and 25 $\mu \mathrm{M}$ 6,7-dinitroquinoxaline-2,3-dione (DNQX) were added. F-I plots were compiled from $1.2 \mathrm{~s}$ depolarizing steps delivered by the clamp every $5 \mathrm{~s}$ from a holding potential of $-60 \mathrm{mV}$. After each step, the magnitude of the injected current was increased by $100 \mathrm{pA}$.

Exsanguination before slice preparation was necessary to eliminate autofluorescence from blood vessels for post hoc immunofluorescence. When possible, $100 \mathrm{~ms}$ negative current injections were given at $1 \mathrm{~Hz}$ at the end of recordings for up to $5 \mathrm{~min}$ to aid in filling the cell with the positively charged fixable polar tracer Alexa Fluor 488. The slice was fixed in $5 \mathrm{ml}$ ice-cold $4 \%$ paraformaldehyde in $1 \times$ DPBS for $1-2 \mathrm{~h}$, after which slices were transferred to $40 \%$ sucrose in $1 \times$ DPBS with sodium azide until resectioning at $40 \mu \mathrm{M}$. Slices were protected from light.

Action potential waveform data from DCN neurons and spike rate data were analyzed in Minianalysis v. 6.0.3 using the following settings. In the main window: threshold $=20 \mathrm{mV}$; period to search a local maximum $=1000 \mu \mathrm{s}$; time before a peak for baseline $=750 \mu \mathrm{s}$; period to search a decay time $=1000 \mu$ s; fraction of peak to find a decay time $=$ 0.05 ; period to average a baseline $=200 \mu \mathrm{s}$; area threshold $=3.5$; number of points to average a peak $=3$. Spike rate data were compiled from the detected peaks by calculating interevent intervals and viewing the column statistics in the Data Array menu. Spike waveform measurements were then taken by marking the detected events as group 1 and clicking Group Analysis in the Events menu. In Group Analysis the gain was set at 20 and four blocks were analyzed per event. Events were analyzed as individual aligned at rise. Baseline was set to zero and the threshold was used as the baseline. Threshold was detected as the peak of the second differential using heavy filtering (smoothing set to 80 points). Data from 10 spikes were analyzed per cell and the average was obtained from column statistics in the Results menu. Input resistances were measured by taking the linear slope of the $I-V$ curves from a subthreshold voltage of $-60 \mathrm{mV}$.
Table 1. Restoration of Kv3.3 function in Purkinje cells of Kcnc1/Kcnc3-null mice does not rescue wild-type motor performance

\begin{tabular}{lllllll}
\hline \multirow{2}{*}{ Genotype } & \multicolumn{2}{l}{ Beam crossings } & & \multicolumn{2}{l}{ Falls of able mice } & \\
\cline { 2 - 3 } & Day 1 & Day 5 & & Day 1 & Day 5 & Lateral deviation \\
\hline$+/+;+/+$ & $49 / 49$ & & & 0 & & $0.44 \pm 0.02(45)$ \\
$-/-;-/-$ & $11 / 21$ & $13 / 21$ & & $4.4 \pm 0.7^{* *}$ & $2.6 \pm 0.6^{*}$ & $1.54 \pm 0.09^{* *}(21)$ \\
$-/-;-/-\mathrm{R}$ & $11 / 21$ & $14 / 21$ & & $4.7 \pm 1.2^{* *}$ & $3.0 \pm 0.8^{* *}$ & $1.56 \pm 0.09^{* *}(19)$ \\
\hline
\end{tabular}

The proportion of mice capable of traversing the $2 \mathrm{~cm}$ beam out of total mice tested is shown under beam crossings. "Falls of able mice" refers to the mean number of falls from five traversals of the $100-\mathrm{cm}$-long, 2-cm-wide beam. Lateral deviation shows the LDls obtained from force-plate actometer test. " $R$ " denotes Purkinje cell Kv3.3 rescue. Where appropriate, means \pm SEM are shown, and significant differences by ANOVA are indicated as follows: ${ }^{*} p<10^{-4} ;{ }^{* *} p<10^{-6}$. Sample sizes are in parentheses at right.

Graphs were presented using Prism. Action potential data were presented using Igor Pro (Wavemetrics) and not corrected for the junction potential. Differences by two-way ANOVA in the $F-I$ relation were derived from multiple comparisons using the Bonferroni correction.

\section{Footprint analysis}

The paws of adult mice were dipped in India ink and the mice were allowed to ambulate at will on bench paper to the end of a tubular tunnel $\sim 3.5$ inches in diameter. Forepaws were inked blue while hindpaws were inked red. The most regular, consistent samples of gait uninterrupted by pauses spanning three consecutive strides were selected for analysis from each mouse. Mice that never produced such samples of gait after three trials were excluded from the analysis. The distances between the centers of (sole defined as center) three consecutive hindpaw prints on one side of the body were averaged and taken as the stride length. Stance width was taken as the average of distances separating every four opposing hindpaw print centers perpendicular to the walking trajectory. Gait was defined as $100 \%$ alternate if each paw print was equidistant between preceding and succeeding opposite paw prints or $0 \%$ if exactly opposite a contralateral paw print (hopping). The distance between each of the consecutive paw prints (side 1) and the closest, preceding or succeeding, opposite (side 2) paw print was multiplied by $200 \%$, and the product divided by the distance between preceding and succeeding opposite paw prints (stride length, side 1) to obtain the percentage value quantifying alternate gait. Values from three consecutive strides were averaged. Paw discordance was taken as the average of the distances between the centers of each hindpaw print and the nearest forepaw print for each of eight pairs of forepaw and hindpaw prints from consecutive strides.

\section{Results}

The rescue of coordination in Kcnc3-null mice and in mice additionally lacking one Kcnc1 allele by restoration of Kv3.3 in Purkinje neurons does not extend to Kcnc1/Kcnc3 double mutants

Previously we reported that re-expressing Kv3.3 channels in Purkinje cells restored fast spiking and coordination in Kcnc3-null mice $(+/+;-/-)$ completely and in $+/-;-/-$ mice partially. Here, we also tested whether re-expression of Kv3.3 channels in Purkinje cells in $-/-;-/-$ mice could reverse the more severe lateral deviation during ambulation and the difficulty traversing a narrow beam. Even on a $2-\mathrm{cm}$-wide beam, - /-; - - mice make too many slips to count and so falls were counted instead. Mice were tested on a 100-cm-long, 2 -cm-wide beam during 5 consecutive days. In contrast to wild-type $(+/+;+/+)$ mice, which had no problems traversing the $2 \mathrm{~cm}$ beam without any falls even on the first day and were therefore not tested on consecutive days, only 11 of $21-/-;-/-$ mice and 11 of $21-/-;-/-$ mice with Kv3.3 restored to Purkinje cells $(-/-;-/-\mathrm{R})$ could traverse the beam (Table 1). Even after $5 \mathrm{~d}$ of training, only 13 of $21-/-$; $-/-$ mice and 14 of $21-/-;-/-$ rescue mice were able to traverse the beam. For the mice that were able to cross the beam we counted falls, and the averages for the first and fifth days are shown in Table 1 . Both $-/-;-/-$ and $-/-;-/-$ rescue mice 
made significantly more falls than wild-type controls on day 1 (ANOVA, $p<10^{-6}$ ) and day $5\left(p<10^{-4}\right.$ and $\left.p<10^{-6}\right)$, and the two $-/-;-1-$ groups did not differ from each other $(p>$ 0.8 ). Falls were not coincident with myoclonic jerks of $-/-;-/-$ mice, suggesting falls were not merely caused by jerks. Similarly, increased lateral deviation on the force plate actometer was not corrected at all in $-/-;-/-$ rescue mice $\left(p<10^{-6}\right)$. In summary, the data indicate that the restoration of Kv3.3 activity in Purkinje cells no longer sufficed to rescue coordination upon loss of both Kcncl alleles. This is in contrast to the partial and the complete rescue after restoration of Kv3.3 activity in Purkinje cells on the $+/-;-/-$ and $+/+;-/-$ backgrounds, respectively (Hurlock et al., 2008).

\section{Loss of Kcnc alleles affects gait pattern}

Lateral deviation of the center of gravity from the main movement trajectory during ambulation and slips while traversing a narrow beam could reflect either abnormal paw placement due to abnormal gait per se (gait pattern), excessive application force, as in jerky movements when fine motor speed is dysregulated, or both. A further possibility is that the timing of movement execution is impaired. When mice lacking Kcnc3 alleles slip on the beam they display jerky movement, although grip strength is intact (Hurlock et al., 2008). Typically, cerebellar ataxias involve disturbances both in gait pattern and the speed of movement, as well as in precise timing of movement execution. Overshoots in movement speed that position the limb beyond the target, or hypermetria, may impart a jerky character to stepping. In addition, hypermetria implies excess force being applied to the plate because smooth deceleration at the end of a movement is impaired. Therefore, we endeavored to determine whether the ataxia stemmed from impaired motor timing, gait patterning, or hypermetria.

We used the DigiGait treadmill to evaluate whether $+/+$; $-/-$ mice are impaired in a simple motor task of running at higher speeds, presumably more sensitive to deficits in fine motor timing (see Materials and Methods and supplemental Fig. S1, available at www.jneurosci.org as supplemental material). Given the impairments noted in complex spikes of Purkinje cells in these mice and their posited role in motor timing (Hurlock et al., 2008), we would expect the maximal breakpoint ambulation speed attained by $+/+;-/-$ mice to be lower than that of $+/+$; $+/+$ mice. Instead, the maximal speeds of $+/+;+/+$ and $+/+;-/-$ mice were not significantly different $(48 \pm 2.7 \mathrm{~cm} / \mathrm{s}$ for $+/+;+/+$ and $45 \pm 2.7 \mathrm{~cm} / \mathrm{s}$ for $+/+;-/-; p=0.47$ ) suggesting that the major deficit in $+/+;-/-$ mice underlying slips on the beam and lateral deviation originates from something other than timing of rapid, repetitive movements (supplemental Fig. $\mathrm{S} 1 A$, available at www.jneurosci.org as supplemental material).

To directly test whether gait is altered, we measured gait parameters with the DigiGait system and performed footprint analysis. The DigiGait treadmill provides semiautomated measurement of gait from paw prints discerned by computer from videos of the rodent taken from beneath a transparent belt and yields numerous measures of gait. All gait parameters measured by the system, including stride length and stance width among other measures often disrupted in ataxia, did not differ between $+/+;+/-$ and $+/-;-/-$ mice (paw areas, which can affect several measurements, were comparable between genotypes) (supplemental Fig. S1 B, $C$, available at www.jneurosci.org as supplemental material). DigiGait analysis yields numerous measures of gait except a continuous measure of alternating gait and paw discordance, which is the dissonance between the forepaw and hindpaw prints.

We next used footprint analysis chiefly because $-/-;-/-$ mice cannot perform on the DigiGait treadmill. Self-paced gait was measured when mice walked on paper with their forepaws and hindpaws inked different colors (see Materials and Methods). We examined stride length, stance width, alternating gait, and paw discordance as a function of Kcncl alleles on the Kcnc3null background. Kcnc3-null mice $(+/+;-/-)$ did not differ from wild-type mice in stride length, stance width, alternating gait, or paw discordance $(p>0.05)$ (Fig. $2 A-D)$. Mice additionally heterozygous for $K c n c 1(+/-;-/-)$ were also identical to wild-type and $+/+;-/-$ mice in stride length, stance width, and alternating gait; importantly, however, they differed in paw discordance, which was significantly greater than in wild-type and $+/+$; $-/-$ mice $(p<0.05)$ (Fig. $2 A-D)$. Thus, intriguingly, gait was essentially unaltered in mice lacking both Kcnc3 alleles as long as a $\mathrm{K} c n c \mathrm{l}$ allele remained despite the poor beam performance of $+/+;-/-$ mice (Hurlock et al., 2008). These findings suggest dissociation between beam slips and gait pattern abnormality. In summary, the data suggest that increased lateral deviation in $+/+;-/-$ mice stems from a problem with force itself rather than abnormal gait.

$K c n c 1 / K c n c 3$ double mutants $(-/-;-/-)$ showed all the signs of cerebellar gait ataxia. Compared to $+/+;+/+$ mice, $-/-;-/-$ mice exhibited a veering path, shortened stride length $(p<0.001)$, widened stance width $(p<0.001)$, decreased alternate gait $(p<0.001)$ (Fig. $2 A-C)$, with occasional frank hopping, and paw discordance (Fig. 2D) that reached high significance when normalized to stride length $(p<0.001)$ (Fig. $2 E$ ). Because stride length is typically decreased and stance width increased in cerebellar ataxia, we normalized stance width to stride length. Accordingly, taken as this ratio, an even greater difference emerged between wild-type and $-1-;-1-$ mice $(p<$ 0.001 ) (Fig. $2 F$ ) than was evident assessing stance width or stride length alone (these data are also summarized in supplemental Table S1, available at www.jneurosci.org as supplemental material). In $+/-;-/-$ mice, therefore, gait ataxia surfaces as paw discordance, and when $K c n c 1$ is ablated altogether, alternating gait along with stride length and stance width is disrupted as well. The paw discordance of $-/-;-/-$ mice was significantly worse than that of $+/-;-/-$ mice $(p<0.05)$ (Fig. $2 E$ ) when normalized to stride length, which is shorter in $-/-;-/-$ mice (Fig. $2 A)$. Finally, restoration of Kv3.3 function to Purkinje cells (Hurlock et al., 2008) did not rescue the normal gait pattern in either $+/-;-/-$ or $-/-;-/-$ mice, for gait parameters both did not differ significantly from mutants and remained significantly different from wild-type mice. These results together point to a more profound disturbance of cerebellar output from the DCN in $-1-;-/-$ mice not alleviated by restoring Purkinje cell output to the DCN resulting in abnormal gait and, perhaps, further changes in force/speed. The jump in severity as Kcncl alleles are lost is congruent with the notion of functional redundancy between Kv3.1 and Kv3.3 channels in DCN projection neurons. We therefore next assessed the intrinsic spiking parameters in projection neurons of the DCN, the final arbiter of cerebellar output.

\section{Altered properties of Kcnc allele-deficient DCN neurons}

We recorded action potentials in DCN neurons lacking Kcnc alleles and wild-type controls using whole-cell patch-clamp recordings in acute slices at $35^{\circ} \mathrm{C}$. We chose to focus on the large projection neurons because these are the principal population known to express Kv3.1 and Kv3.3 in the DCN and the one that 

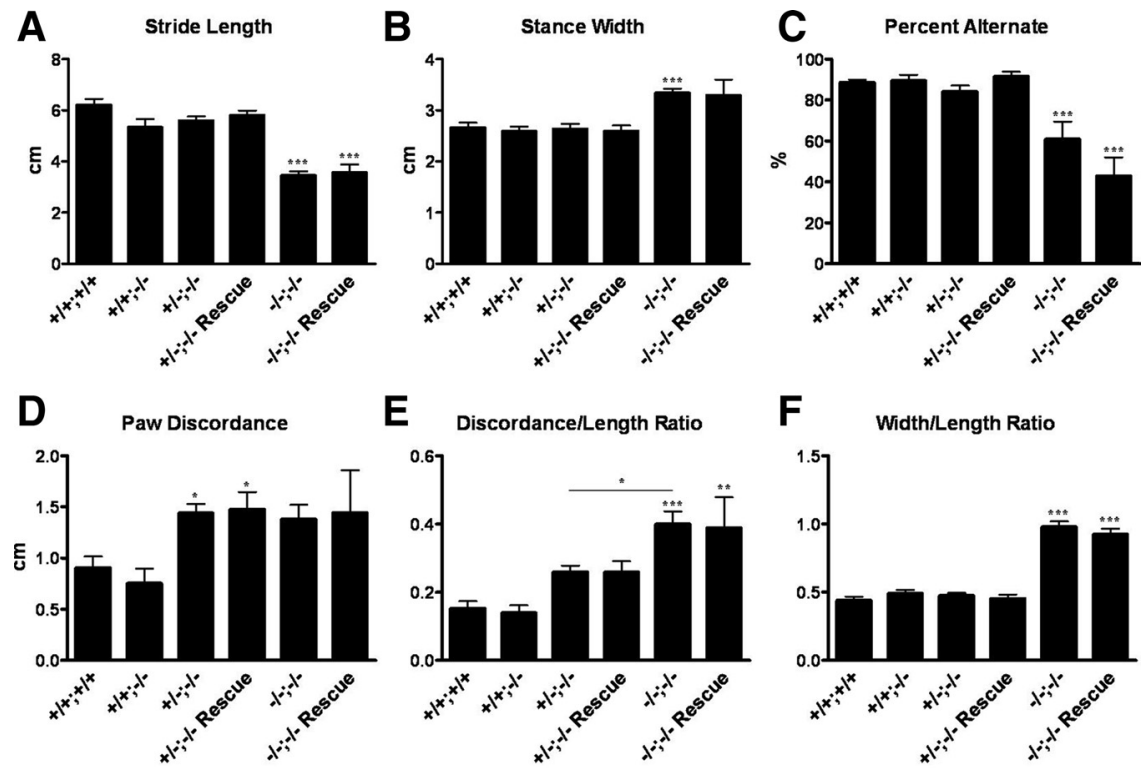

E Discordance/Length Ratio

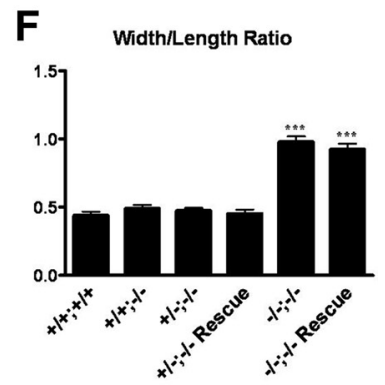

G
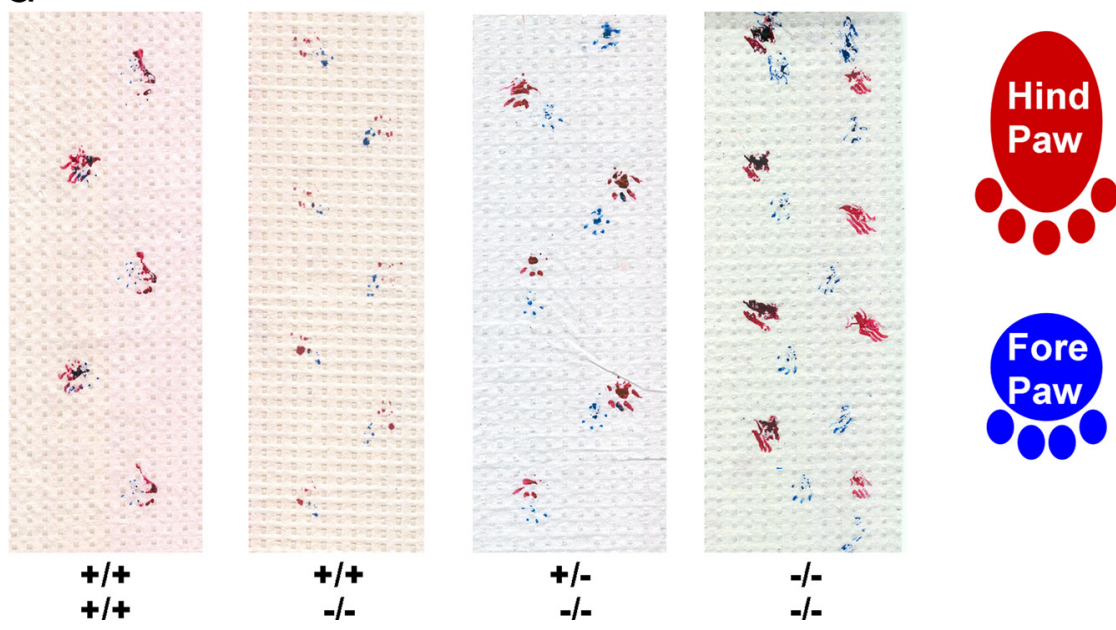

Figure 2. Progressive perturbation of gait as Kcnc 1 alleles are ablated. $\boldsymbol{A}-\boldsymbol{F}$, Hindlimb stride length $(\boldsymbol{A})$, hind stance width $(\boldsymbol{B})$, percentage alternate gait where perfectly antiphase stepping is $100 \%$ alternate $(\boldsymbol{C})$, discordance between the placement of the forepaw and hindpaw $(\boldsymbol{D})$, paw discordance normalized to stride length (ratio of D/A) $(\boldsymbol{E})$, and stride length normalized to stance width $(\mathrm{A} / \mathrm{B})(\boldsymbol{F})$ are all affected in $-/-;-/-$ mice (ANOVA; ${ }^{*} p<0.05 ;{ }^{* * *} p<0.001 ;+/+;+/+n=11 ;+/+;-/-n=$ $6 ;+I-;-I-n=4 ;-I-;-I-n=8) . G$, Raw self-paced footprint data inking the forepaws blue and hindpaws red $(+/+;$ $+I+, n=17 ;+I+;-I-, n=5 ;+I-;-I-, n=10 ;+I-;-I-$ rescue, $n=9 ;-I-;-I-, n=9 ;-I-;-I-$, rescue $n=3)$. $\mathbf{G}$ is with kind permission from Springer Science + Business Media: The cerebellum: The role of Kv3-type potassium channels in cerebellar physiology and behavior; Vol 8 Number 3; 2009; pp 323-333; Joho RH, Hurlock EC; Figure 6. classified as weak burst showed a lowerfrequency burst at a short latency consisting of many fewer spikes.

Spontaneous action potentials were measured without current injection. The large, weak-bursting DCN neurons displayed graded differences in their action potential properties and ability to spike at high frequencies as function of genotype. Cells from $+/+;-/-$ mice showed perhaps only a subtle alteration whereas DCN neurons additionally lacking one or two Kcncl alleles exhibited more pronounced, significant alterations (Fig. $4 A-F$ ). Importantly, loss of Kv3 subunit genes did not affect input resistance, suggesting that recordings were comparable despite the high variability presumably due to the great morphological diversity among large DCN neurons (Chan-Palay, 1977).

The mean action potential width at half-amplitude was greater in mutant DCN neurons than in the wild type $(0.18 \pm 0.1 \mathrm{~ms})$, reaching significance in Kcnc3-null mice lacking a Kcnc1 allele $(0.27 \pm 0.01 \mathrm{~ms})$, where spikes were $\sim 50 \%$ broader (ANOVA, $p<0.001$ ) (Fig. $4 B)$, and in $-/-;-/-$ mice $(0.39 \pm 0.02$ $\mathrm{ms})$, where spikes were broadened in excess of $\sim 100 \%(p<0.001)$. The width in $-/-;-/-$ mice is moreover significantly greater than that of $+/+;-/-$ mice $(0.22 \pm 0.01 \mathrm{~ms} ; p<0.001)$ or $+/-$; - /mice $(p<0.001)$ (Fig. $2 B)$. The fast afterhyperpolarization amplitude also appears to diminish with decreased Kcncl gene dosage, while the time it takes for the membrane potential to decay to $90 \%$ of the difference between the action potential and afterhyperpolarization peaks significantly increases for $+/-;-/-$ and $-/-;-/-$ mice $(p<0.001)$ (Fig. $4 C)$, in part reflecting the reduction of the fast afterhyperpolarization. This decay time is significantly slower in $-/-;-/-$ mice $(p<0.001)$ and even $+/-;-/-$ mice conveys information to motor centers likely relevant to motor coordination (Fig. 1). To compare neurons of the same type to each other, we identified neurons post hoc with confocal fluorescence microscopy by filling with a fixable polar tracer, Alexa Fluor 488 (Fig. 3A-C). Glutamatergic projection neurons were evidenced by their large size (Chan-Palay, 1977; Kumoi et al., 1988; Batini et al., 1992; Aizenman et al., 2003). In contrast to other brain areas in the DCN, it is the large neurons that are relatively fast spiking (Uusisaari et al., 2007). We restricted our analysis to the apparent murine counterpart of the weak-burst subtype classified in rat (Molineux et al., 2006 and 2008) by their distinctive electrophysiological signature in response to depolarizing current injection steps or upon relief of hyperpolarizing current steps (Fig. 3D,F,H). The abundances of these strongburst neurons were as follows: $1 / 13$ in $+/+;+/+, 4 / 10$ in $+/+$; $-/-, 0 / 5$ in $+/-;-/-$, and $1 / 9$ in $-/-;-/-$ mice. Those we $(p<0.01)$ than in mice just lacking Kcnc3 $(+/+;-/-)$.

Along with the spike width and decay time, the spike amplitude is significantly greater in the mutants (for $+/+$; $+/+$, $57.7 \pm 2.0 \mathrm{mV}$; for $+/+$; $-/-, 67.6 \pm 1.9 \mathrm{mV}$; for $+/-$; $-/-$, $69.3 \pm 3.7 \mathrm{mV}$; and for $-/-;-/-, 72.6 \pm 1.8 \mathrm{mV}$ ), and in this case the difference between the wild type and mice lacking Kcnc3 $(+/+;-/-)$ is significant $(p<0.05)$ (Fig. $4 D)$. The spike rise time, however, did not undergo a significant change (Fig. $4 E$ ). In summary, the spike width and height increase and the fast afterhyperpolarization decreases progressively when one or two Kcnc1 alleles are lacking (summarized in supplemental Table S2, available at www.jneurosci.org as supplemental material).

We also measured interspike intervals 4 min after going into the whole-cell recording configuration (Fig. $4 F$ ). Interspike intervals of spontaneous, tonic spikes were significantly increased only in $-/-;-/-$ mice, corresponding to a decreased firing 
frequency $(\sim 50 \mathrm{~Hz})$ compared to the wild type $(\sim 100 \mathrm{~Hz}$; ANOVA, $p<0.05)$ (supplemental Table S2, available at www. jneurosci.org as supplemental material). This twofold difference in the spontaneous spike rate parallels the difference in spike width between wild-type and -/-; $-/-$ mice. The coefficient of variance of the interspike interval was not increased over that of the wild type in $-/-;-/-$ mice (ANOVA, overall $p=0.26$ ).

Since Kv3 current preferentially affects high spike rates, we measured frequency as a function of injected depolarizing current $(F-I)$. We first examined the slope of the $F-I$ relation. The $F-I$ relation appeared to differ among genotypes such that mutants with greater spike broadening exhibited a more shallow slope on the F-I plot consistent with a more severe impairment in firing at high frequencies (Fig. $4 G, H$ ). These differences in slope were on the cusp of significance (ANOVA; $p=0.05)$. We then assessed differences in the $F-I$ relation by two-way ANOVA examining the effect of genotype at varying current intensities as variables. At the three strongest current intensities shown, we found $-1-;-1-$ frequencies to be significantly lower than the wild type. We restricted analysis to a range of intensities over which all cells of all genotypes could spike sustain spiking. Thus, the data presented here may if anything underestimate the difference between genotypes most evident at higher frequencies omitted from analysis. Altogether, the $F-I$ relation indicates that loss of Kcncl alleles has a more pronounced effect on firing at high frequencies that in weak-burst neurons may be reached during strong excitatory synaptic input from climbing or summated mossy fiber input (Zhang et al., 2004; Pugh and Raman, 2006).

\section{Kv3 channel expression in DCN}

That only complete loss of Kcncl and Kcnc3 is correlated with the emergence of the full repertoire of cerebellar ataxia signs, restoration of Kv3.3 to Purkinje cells upstream of the DCN fails to rescue motor performance, and spiking becomes abnormal only once Kcncl alleles are lost suggests these genes exhibit functional redundancy in DCN neurons. For this to be the case, Kv3.1 and Kv3.3 subunits must be expressed in the same cells, presumably large, glutamatergic projection neurons, which are inferred to be those endowed with especially brief action potentials (Uusisaari et al., 2007). To determine the distribution of Kv3 channels in the DCN and validate the neurochemical identity of large cells, we performed immunostaining with Kv3 channel-specific antibodies. We focused our study on the medial nucleus. Essentially all recordings came from this nucleus or its immediate environs in the interpositus.

We found that Kv3.1 and Kv3.3 are expressed together in the large, glutamatergic projection neurons using markers for these cells. Previously, Kv3.1 and Kv3.3 subunits were both separately found to be expressed in large DCN neurons (McMahon et al., 2004). Recently, SMI-32/neurofilament H (Hoshino et al., 2005) and parvalbumin (Marzban and Hawkes, 2007) have been described as markers distinguishing the large, glutamatergic projection neurons in the DCN. Here we obtained direct evidence using antibodies from different species that these subunits are indeed expressed together (Fig. 5A-D) in all large, glutamatergic projection neurons visualized by antibodies to SMI-32 and negative for GAD67 (Fig. 5E). Kv3.3 is shown here with these markers. Because Kv3.1 is present in all DCN neurons expressing Kv3.3, we obtained indirect evidence that Kv3.1 is present in SMI-32positive, GAD67-negative neurons. Kv3.1 and Kv3.3 expression is enriched in the plasma membrane, as expected, corroborating previous work examining subunits separately (McMahon et al., 2004). That somatic Kv3.3 signal is inherent to large neurons and distinct from staining derived from Purkinje cell terminals is supported by a lack of colocalization with calbindin (Fig. $5 H$ ), which uniquely distinguishes Purkinje cells in the cerebellum (Séquier et al., 1990). Parvalbumin is also localized to glutamatergic neurons in the DCN, and we saw coexpression of parvalbumin with 
A
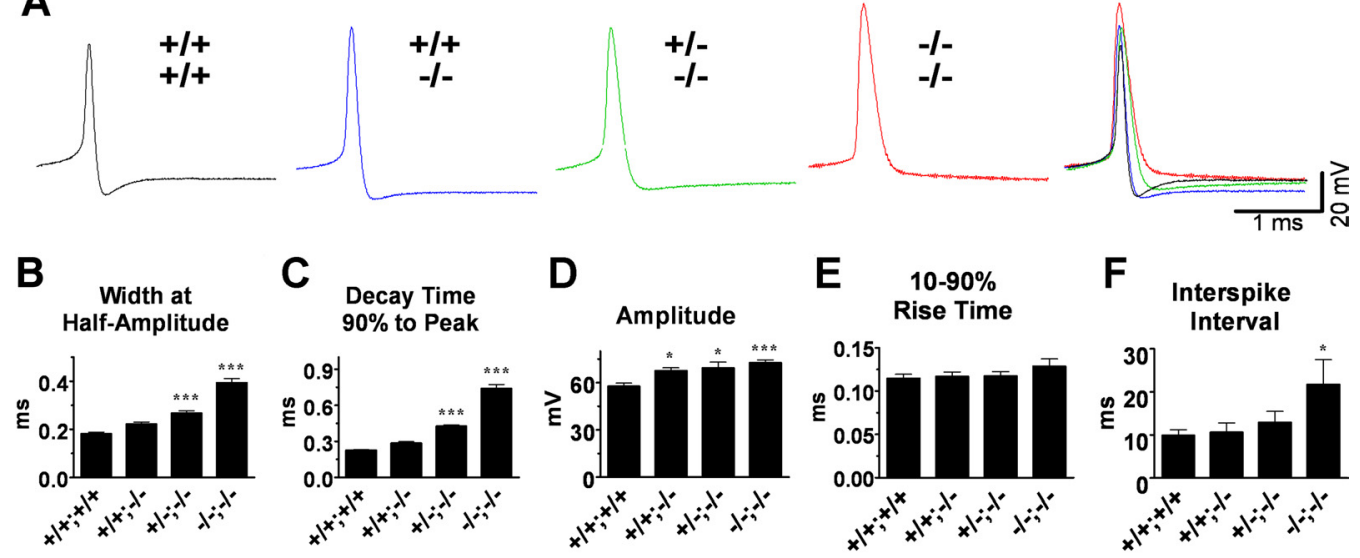

G

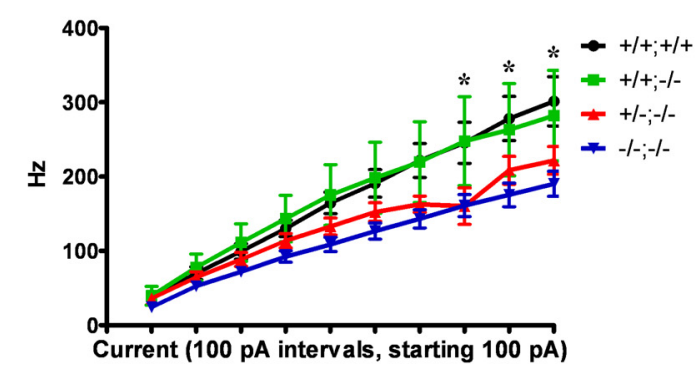

$\mathrm{H}$

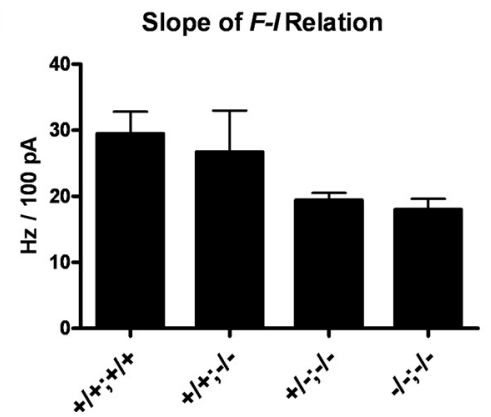

Figure 4. Spike waveform properties and frequency as a function of injected current ( $F-I$ relation) in large, glutamatergic DCN neurons lacking variable numbers of $K c n c 1$ and $K c n c 3$ alleles. $A$, Representative traces of individual, spontaneous, regular action potentials in large, weak-burst DCN neurons across genotypes with an overlay at right show broadening, heightening, and loss of the fast afterhyperpolarization as $K c n c 1$ alleles are lost (supplemental Table $\$ 2$, available at www.jneurosci.org as supplemental material). $\boldsymbol{B}-\boldsymbol{F}$, Spike width at half-amplitude (B); Decay time $90 \%$ from peak to peak of the afterhyperpolarization (C); Spike amplitude measured threshold to peak (D); $10-90 \%$ threshold-to-peak spike rise time $(\boldsymbol{E})$; Interspike interval measured peak to peak from spontaneous, regular spikes recorded intracellularly $(\boldsymbol{F})$. Significant differences from the wild type are indicated (ANOVA, ${ }^{*} p<0.05 ; *{ }^{* *} p<0.01 ; * * * 0.001 ;+/+;+/+n=11 ;+/+;-/-$ $n=6 ;+/-;-I-n=4 ;-I-;-I-n=8) . \mathbf{G}, F-/$ plot. Significant differences $(p<0.05 ; 2$-way ANOVA, Bonferroni correction) from the wild type are indicated by an asterisk. $\boldsymbol{H}$, Average slopes of the $F-$ I relation are shown $(+/+;+1+, n=9 ;+1+;-1-, n=4 ;+1-;-1-, n=5 ;-1-;-1-, n=6)$. $A$ is with kind permission from Springer Science + Business Media: The cerebellum: The role of Kv3-type potassium channels in cerebellar physiology and behavior; Vol. 8 Number 3; 2009; pp 323-333; Joho RH, Hurlock EC; Figure 6.

SMI-32 consistently in large neurons (data not shown), buttressing the notion that SMI-32 distinguishes these cells. Moreover, large neurons identified by Nissl staining that extends into the cytoplasm (Fig. 5E) are SMI-32 positive and GAD67 negative (data not shown). DCN neurons with areas of more than $\sim 300$ $\mu \mathrm{m}^{2}$ are consistently GAD67 negative (Uusisaari et al., 2007). These observations support the notion that the large neurons identified by Alexa Fluor 488 fills after intracellular recording (Fig. $3 A-C$ ) are the glutamatergic projection neurons. In addition, the immunohistochemical data provide a potential basis for the apparent functional redundancy between Kcnc1 and Kcnc3 seen in the electrophysiological and behavioral data.

Kv3.2 and Kv3.4 mRNA (Weiser et al., 1994; Lau et al., 2000), as well as protein in the former case, are detected in the DCN; however, unlike Kv3.1, these Kv3 subunits do not fully complement the loss of Kv3.3. To determine whether these subunits are present in large neurons, we performed triple immunofluorescence with SMI-32 and GAD67. Although we did observe Kv3.2 (Fig. 5F) and Kv3.4 (Fig. 5G) subunits coexpressed with SMI-32 but not GAD67, curiously the signals for both did not exhibit the characteristic enrichment in the membrane seen with Kv3.1 and Kv3.3, only the much lower, diffuse cytoplasmic staining. Both Kv3.3 and Kv3.4 were detected in SMI-32-positive axons of Purkinje cells distinguished by GAD67 in the DCN entering from the folia (Fig. $5 E, G$ ). Kv3 channels have never been reported in mossy or climbing fibers, and Kv3.3 invariably colocalizes with calbindin, consistent with the axons being those of Purkinje cells.
Kv3.3 appears to be in the membrane of GAD67-positive presumed synaptic terminals studding DCN neurons (Fig. $5 E$ ) that coexpress calbindin (Fig. $5 H$ ). Again, Kv3.4 yields a more diffuse label, as it does in Purkinje cell somata. The diffuse staining does not likely reflect an artifact, since in Purkinje cells the stronger punctate labeling described before (Martina et al., 2003) in dendrites is seen on the same sections. We did not see many GAD67positive neurons, probably because they are sparse in the medial nucleus analyzed when parasagittal sections are used (Molineux et al., 2006). Staining for Kv3.4, we found one such cell and it expressed the subunit (data not shown). Here, as in somata of GAD67-negative neurons and presumed Purkinje cell terminals, Kv3.4 does not appear to be enriched in the membrane. Thus, the immunohistochemical and electrophysiological data suggest that in large, weak-burst DCN projection neurons the bulk of fast repolarization is imparted by Kv3.1 together with possibly Kv3.3 channels.

\section{Discussion}

DCN neurons are underscored as a potential locus where Kcnc1-dependent fast repolarization is necessary for normal gait patterning and to rescue motor coordination in Kcnc3-null mutants after restoration of Kv3.3 function in Purkinje cells

We found that Purkinje cell fast repolarization is related to supporting normal motor speed rather than timing or gait patterning. As Kcnc1 alleles are lost on a Kcnc3-null background, graded 


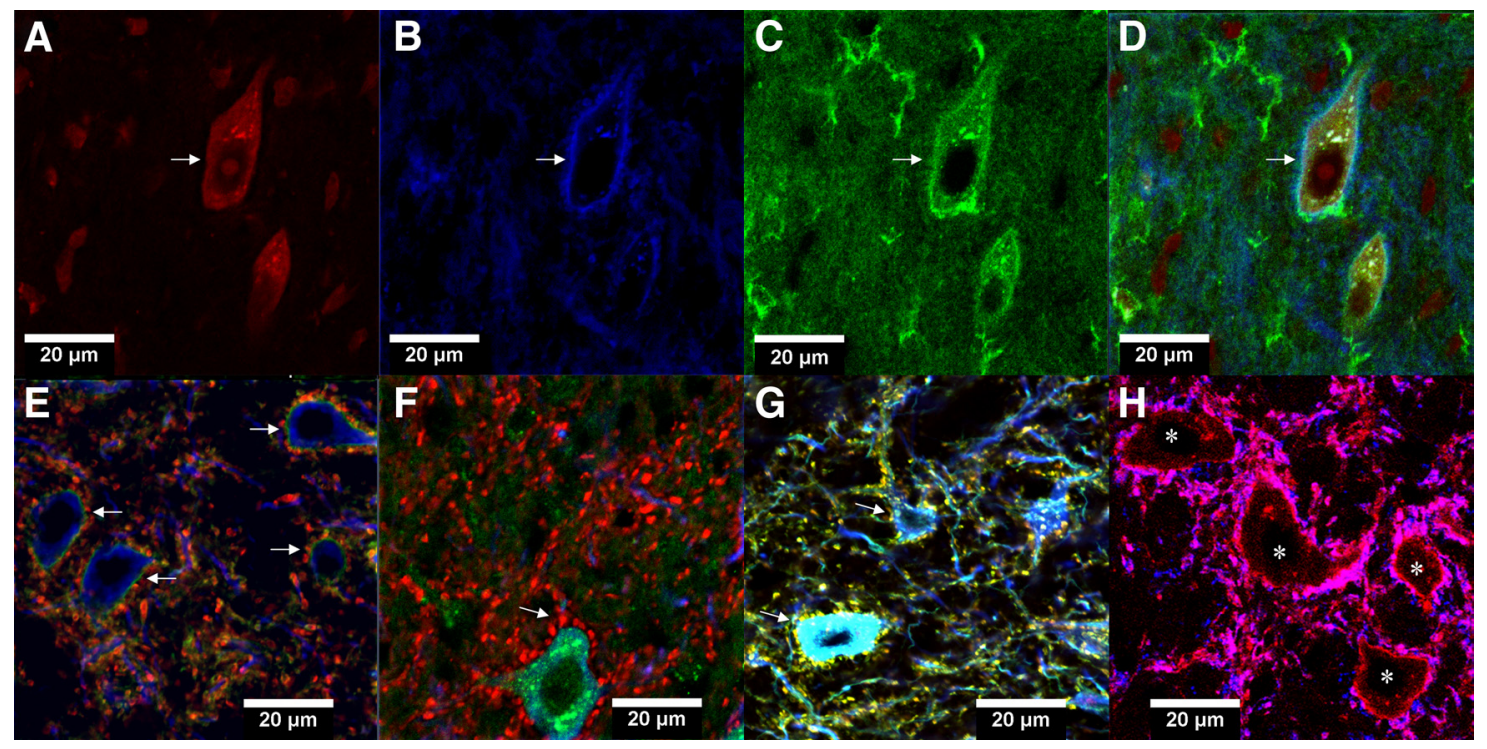

Figure 5. Immunofluorescent staining showing coexpression of all four Kv3 subunits in large, glutamatergic DCN neurons marked by SMI-32. A, Nissl staining (red) is present in the cytoplasm demarcating a large neuron indicated by an arrow. $\boldsymbol{B}$, Kv3.3 (blue) is present enriched in the membrane and presynaptic innervation (also see $\boldsymbol{H}$ ) of a large neuron indicated by an arrow. $\boldsymbol{C}$, Kv3.1 (green) is present enriched in the membrane of a large neuron indicated by an arrow. D, Overlay of $\boldsymbol{A}-\boldsymbol{C}$ showing coexpression of Kv3.1 (green) and Kv3.3 (blue) in a large neuron highlighted by Nissl staining (red) and indicated by the arrow. $\boldsymbol{E}$, Kv3.3 (green) is present consistently in SMI-32-positive (blue), non-GABAergic large neurons (GAD67 is red). Arrows indicate large neurons. $\boldsymbol{F}$, Kv3.2 (green) is present consistently in SMI-32-positive (blue), non-GABAergic (GAD67 is red) large neurons exemplified by the single large neuron studded with GABAergic terminals devoid of Kv3.2, indicated by the arrow. G, Large neurons coexpress Kv3.4 (green) and SMI-32 (blue) but not GAD67 (red), which is found on presumed boutons indicated by the arrows surrounding the soma and proximal dendrites. $\boldsymbol{H}, \mathrm{Kv} 3.3$ (red) is expressed in large neurons (asterisks) without calbindin and in presumed synaptic terminals with calbindin (blue). We performed negative control experiments with Kcnc1- and Kcnc3-null mutant tissue processed in parallel. Only faint staining was detected in DCN neurons and no membrane enrichment was detected.

deficits in gait patterning emerge. Restoration of intrinsic spiking in Purkinje cells loses efficacy in reversing ataxia, in contrast to the complete efficacy seen with Kcncl intact. The data highlight the DCN as a candidate locus whereby loss of $K c n c 1$ alleles could lead to spike changes underlying gait ataxia, caused either by more extreme hypermetria or by an independent deficit disrupting gait patterning seen only once the DCN are affected.

The DCN neurons downstream of Purkinje cells appear in essence normal in $+/+;-/-$ mice, enabling restored Purkinje cell output in $+/+;-/-$ rescue mice to be faithfully transmitted to motor centers (Fig. 1). The intrinsic spike data suggest that the large, weak-bursting DCN projection neurons are only subtly altered in the Kcnc3-null mutant, more so when in addition a $\mathrm{Kcncl}$ allele is missing $(+/-;-/-)$ and markedly when both $K c n c 1$ and $K c n c 3$ are entirely ablated $(-/-;-/-)$.

Whether the loss of fast repolarization in the DCN indeed accounts for the persistence of ataxia in $-1-;-/-$ rescue mice remains uncertain because the combined loss of Kcncl and Kcnc3 alleles in other brain loci, such as the basal ganglia, red nucleus, and pontine nuclei, and even from cerebellar granule cells could contribute to the loss of Purkinje cell rescue efficacy. The ataxic phenotype, however, is characteristic of cerebellar ataxia, suggesting a cerebellar origin (Barboi, 2000; Mariotti et al., 2005). DCN neurons are a prime candidate because disruption of their firing rate and to some extent repolarization by dominantnegative inhibition of SK calcium-activated potassium channels led to deficits correlated with DCN rather than red nucleus expression (Shakkottai et al., 2004).

Loss of granule-cell/parallel-fiber fast repolarization in -1-; $-/-$ mice is less likely to account for the deficits. If it did, we might expect ataxia to correlate with electrophysiological deficits here. In parallel fibers, loss of Kcncl or Kcnc3 alleles leads to graded changes seen even in mice with only a single allele absent that lack an ataxic phenotype and even in $+/+;-/-$ mice (Matsukawa et al., 2003). Despite the altered parallel fiber input to Purkinje cells in $+/+;-/-$ mice, these mice undergo a complete rescue of motor coordination upon Kv3.3 restoration to Purkinje cells, although one might expect continued increased neurotransmitter release due to broader spikes at the granule-toPurkinje cell synapse. Because neurotransmitter release increases in a nonlinear manner as a function of the calcium level, further spike broadening as $\mathrm{Kcncl}$ alleles are lost could however yield a disproportionate augmentation of excitatory drive. Therefore, we cannot categorically exclude a role of granule cells in the loss of rescue efficacy and the markedly increased motor phenotype observed in $-1-;-1-$ mice.

A recent study has revealed Kv3.1 and Kv3.3 expression in approximately half of GAD67-positive neurons that could represent interneurons or those projecting to the inferior olive (Alonso-Espinaco et al., 2008). These cells could be another locus where redundancy could account for the behavior; however, action potentials of wild-type GAD67-positive neurons are already considerably broader than in large neurons (Uusisaari et al., 2007). Finally, another factor that could explain the lack of a coordination rescue in $-1-;-1-$ mice is the presence of other, superimposed motor phenotypes that may be independent of cerebellar function. In particular, in contrast to $+/-;-/-$ mice, $-/-;-/-$ mice cannot sustain their grip when held inverted on a cage lid (unpublished observation), although if this reflects grip strength and not merely frequent myoclonus it would not explain the failure to even partially restore normal lateral deviation in $-1-;-1-$ mice.

In humans, spinocerebellar ataxia 13 (SCA13) is caused by dominant-interfering mutations in $\mathrm{KCNC} 3$-encoded $\mathrm{Kv} 3.3$ subunits (Waters et al., 2006). Such dominant-negative Kv3.3 subunits would be expected, through heterotetramer formation, to disrupt all Kv3 currents in which mutant $\mathrm{Kv} 3.3$ subunits are present, causing symptoms to extend beyond those in Kv3.3-null 
mutants arising from disrupted firing of cells that depend solely on Kcnc3 for fast repolarization to symptoms related to cells wherein there is redundant subunit expression. SCA13 patients present with both gait ataxia and dysmetria (Waters et al., 2005). A dominant-negative Kv3.3 subunit may also abolish fast repolarization in cells coexpressing Kv3.1 as in the DCN. Interestingly, in general where lesions perturb DCN output directly cerebellar ataxia tends to be worse than when only Purkinje cell output is impaired (Welsh and Harvey, 1992).

\section{Kv3.3 expression in Purkinje cells is necessary for normal motor speed but not gait pattern}

We found that the slips on the narrow $1 \mathrm{~cm}$ beam and increased lateral deviation in $+/+;-/-$ mice seen previously (Hurlock et al., 2008) are not due to an abnormal gait pattern but rather hypermetric (overshooting velocity) jerky movements. During swimming (unpublished observations) and on the $1 \mathrm{~cm}$ beam, $+/+;-/-$ mice manifested a striking tendency to make jerky kicking movements rather than exhibit smooth, coordinated acceleration and deceleration of movement with precision and finesse. Swimming and regaining of footing on the beam seemed to be impaired by this. Mice kick when trying to place their hind feet back on the beam and jerky movement would be expected to increase the chance of slipping, since mice grasp the side of the beam mostly when walking across. It is unknown whether hypermetria and gait pattern abnormalities are independent or interrelated such that extreme hypermetria can cause the gait abnormalities seen upon loss of Kcnc1 alleles on a Kcnc3-null background. It is also unclear whether muscle twitches are behind the paw discordance seen in $+/-;-/-$ mice; however, it is unlikely because the twitches are not quite frequent enough to alone account for the irregular paw placement. Increased paw discordance described in the present work could alternatively explain why lateral deviation is only partially rescued by restoration of Kv3.3 to Purkinje cells in $+/-;-/-$ mice (Hurlock et al., 2008).

\section{Large, weak-burst neurons exhibit graded spike broadening mirroring behavioral effects when Kcnc1 alleles are lost on the Kcnc3-null background}

The weak-burst, large DCN neurons examined in this study resembled the large GAD67-negative neurons in mouse (Uusisaari et al., 2007). We additionally encountered large neurons with firing more similar to the strong or transient-burst subtype described in rat, albeit at a lower frequency (Zhang et al., 2004; Molineux et al., 2006, 2008). Although the physiological significance of rebound bursting has become contentious (Alviña et al., 2008), it will be interesting for future work to evaluate changes in the strong-burst subtype, for it is during rebound bursts of these cells following inhibitory input that fast-spiking DCN projection neurons fire at a higher rate and therefore could be more profoundly affected upon loss of fast repolarization. The twofold difference in the spontaneous spike rate and width seen in Purkinje cells lacking Kv3.3-dependent fast repolarization parallels the difference in spike width of DCN neurons between wild-type and $-/-;-/-$ mice, consistent with functional redundancy in the DCN given that Purkinje cells do not express Kv3.1 protein. Intriguingly, it appears that in the cerebellum only Kv3.1 and $\mathrm{Kv} 3.3$ are able to keep action potentials fast in the range of widths at half-heights of $0.15-0.2 \mathrm{~ms}$, while Kv3.2 and Kv3.4 may delimit the duration only to $0.3-0.4 \mathrm{~ms}$ based on the $-/-$; - /recordings. One possible explanation is that the latter two subunits contribute less to repolarization because they are expressed at lower levels or that their kinetics are slower. Ablation of Kcnc2 or Kcnc4 could yield insight as to whether these subunits contribute to repolarization or have another cellular function.

The interpretation of the immunohistochemical data is limited by the existence of several splice variants, encoded by the different Kcnc genes, carrying distinct $\mathrm{C}$ termini. Antibodies to $\mathrm{Kv} 3.1$ and Kv3.3 subunits used in this study detect only the major isoform(s). An absence of membrane accumulation of Kv3.2 and Kv3.4 cannot be explained by failure to detect a specific splice variant because the antibodies used targeted the invariant $\mathrm{N}$ termini. While Kv3.1a, Kv3.1b, Kv3.2, and Kv3.3 are all present in axons or at least terminals, only $\mathrm{Kv} 3.1 \mathrm{~b}$ has been detected at nodes of Ranvier (Ozaita et al., 2002; Devaux et al., 2003; Chang et al., 2007). Thus, if Kv3.1b has an important nodal function, we might expect mice lacking only Kcncl to display ataxia; however, interestingly, they do not (Joho et al., 2006). It remains possible that in neurons such as DCN neurons in addition to Kv3.1b other as-yet-undetected $\mathrm{Kv} 3.3$ variants are present at nodes to complement the loss of Kv3.1. It is unknown whether internodal axonal expression merely reflects protein in transit or a local function in the axonal membrane. Therefore, it remains possible that physiologically enigmatic axonal expression of Kv3 subunits could account for the functional redundancy between $K c n c 1$ and $K c n c 3$ as well as the somatic changes in action potentials reported here in null mutants.

In conclusion, DCN neurons represent a compelling candidate locus where Kcnc1-dependent electrophysiological parameters may be essential for the efficacy of the Purkinje-cell-specific Kv3.3 rescue of mutant behavior and the emergence of gait ataxia in $+/-;-1-$ and $-1-;-1-$ mutant mice.

\section{References}

Aizenman CD, Huang EJ, Linden DJ (2003) Morphological correlates of intrinsic electrical excitability in neurons of the deep cerebellar nuclei. J Neurophysiol 89:1738-1747.

Alonso-Espinaco V, Elezgarai I, Díez-García J, Puente N, Knöpfel T, Grandes P (2008) Subcellular localization of the voltage-gated potassium channels Kv3.1b and Kv3.3 in the cerebellar dentate nucleus of glutamic acid decarboxylase 67-green fluorescent protein transgenic mice. Neuroscience 155:1059-1069.

Alviña K, Walter JT, Kohn A, Ellis-Davies G, Khodakhah K (2008) Questioning the role of rebound firing in the cerebellum. Nat Neurosci 11:1256-1258.

Barboi AC (2000) Cerebellar ataxia. Arch Neurol 57:1525-1527.

Bartos M, Vida I, Jonas P (2007) Synaptic mechanisms of synchronized gamma oscillations in inhibitory interneuron networks. Nat Rev Neurosci 8:45-56.

Batini C, Compoint C, Buisseret-Delmas C, Daniel H, Guegan M (1992) Cerebellar nuclei and the nucleocortical projections in the rat: retrograde tracing coupled to GABA and glutamate immunohistochemistry. J Comp Neurol 315:74-84.

Bobik M, Ellisman MH, Rudy B, Martone ME (2004) Potassium channel subunit Kv3.2 and the water channel aquaporin- 4 are selectively localized to cerebellar pinceau. Brain Res 1026:168-178.

Chang SY, Zagha E, Kwon ES, Ozaita A, Bobik M, Martone ME, Ellisman MH, Heintz N, Rudy B (2007) Distribution of Kv3.3 potassium channel subunits in distinct neuronal populations of mouse brain. J Comp Neurol 502:953-972.

Chan-Palay V (1977) Cerebellar dentate nucleus: organization, cytology and transmitters. New York: Springer.

Chesselet MF, Plotkin JL, Wu N, Levine MS (2007) Development of striatal fast-spiking GABAergic interneurons. Prog Brain Res 160:261-272.

Chow A, Erisir A, Farb C, Nadal MS, Ozaita A, Lau D, Welker E, Rudy B (1999) $\mathrm{K}^{+}$channel expression distinguishes subpopulations of parvalbumin- and somatostatin-containing neocortical interneurons. J Neurosci 19:9332-9345.

Devaux J, Alcaraz G, Grinspan J, Bennett V, Joho R, Crest M, Scherer SS (2003) Kv3.1b is a novel component of CNS nodes. J Neurosci 23:4509-4518. 
Espinosa F, McMahon A, Chan E, Wang S, Ho CS, Heintz N, Joho RH (2001) Alcohol hypersensitivity, increased locomotion, and spontaneous myoclonus in mice lacking the potassium channels Kv3.1 and Kv3.3. J Neurosci 21:6657-6665.

Espinosa F, Marks G, Heintz N, Joho RH (2004) Increased motor drive and sleep loss in mice lacking Kv3-type potassium channels. Genes Brain Behav 3:90-100.

Espinosa F, Torres-Vega MA, Marks GA, Joho RH (2008) Ablation of Kv3.1 and $\mathrm{Kv} 3.3$ potassium channels disrupts thalamocortical oscillations in vitro and in vivo. J Neurosci 28:5570-5581.

Fowler SC, Birkestrand BR, Chen R, Moss SJ, Vorontsova E, Wang G, Zarcone TJ (2001) A force-plate actometer for quantitating rodent behaviors: illustrative data on locomotion, rotation, spatial patterning, stereotypies, and tremor. J Neurosci Methods 107:107-124.

Henderson Z, Fiddler G, Saha S, Boros A, Halasy K (2004) A parvalbumincontaining, axosomatic synaptic network in the rat medial septum: relevance to rhythmogenesis. Eur J Neurosci 19:2753-2768.

Ho CS, Grange RW, Joho RH (1997) Pleiotropic effects of a disrupted K ${ }^{+}$ channel gene: reduced body weight, impaired motor skill and muscle contraction, but no seizures. Proc Natl Acad Sci U S A 94:1533-1538.

Hoshino M, Nakamura S, Mori K, Kawauchi T, Terao M, Nishimura YV, Fukuda A, Fuse T, Matsuo N, Sone M, Watanabe M, Bito H, Terashima T, Wright CV, Kawaguchi Y, Nakao K, Nabeshima Y (2005) Ptfla, a bHLH transcriptional gene, defines GABAergic neuronal fates in cerebellum. Neuron 47:201-213.

Hurlock EC, McMahon A, Joho RH (2008) Purkinje-cell-restricted restoration of Kv3.3 function restores complex spikes and rescues motor coordination in Kcnc3 mutants. J Neurosci 28:4640-4648.

Joho RH, Hurlock EC (2009) The role of Kv3-type potassium channels in cerebellar physiology and behavior. In: The cerebellum, Vol 8, Number 3, pp 323-333. New York: Springer Science+Business Media.

Joho RH, Street C, Matsushita S, Knöpfel T (2006) Behavioral motor dysfunction in Kv3-type potassium channel-deficient mice. Genes Brain Behav 5:472-482.

Kasten MR, Rudy B, Anderson MP (2007) Differential regulation of action potential firing in adult murine thalamocortical neurons by Kv3.2, Kv1, and SK potassium and N-type calcium channels. J Physiol 584:565-582.

Kumoi K, Saito N, Kuno T, Tanaka C (1988) Immunohistochemical localization of gamma-aminobutyric acid- and aspartate-containing neurons in the rat deep cerebellar nuclei. Brain Res 439:302-310.

Lau D, Vega-Saenz de Miera EC, Contreras D, Ozaita A, Harvey M, Chow A, Noebels JL, Paylor R, Morgan JI, Leonard CS, Rudy B (2000) Impaired fast-spiking, suppressed cortical inhibition, and increased susceptibility to seizures in mice lacking $\mathrm{Kv} 3.2 \mathrm{~K}^{+}$channel proteins. J Neurosci 20:9071-9085.

Mariotti C, Fancellu R, Di Donato S (2005) An overview of the patient with ataxia. J Neurol 252:511-518.

Martina M, Yao GL, Bean BP (2003) Properties and functional role of voltage-dependent potassium channels in dendrites of rat cerebellar Purkinje neurons. J Neurosci 23:5698-5707.

Marzban H, Hawkes R (2007) Fibroblast growth factor promotes the development of deep cerebellar nuclear neurons in dissociated mouse cerebellar cultures. Brain Res 1141:25-36.

Matsukawa H, Wolf AM, Matsushita S, Joho RH, Knöpfel T (2003) Motor dysfunction and altered synaptic transmission at the parallel fiber-Purkinje cell synapse in mice lacking potassium channels Kv3.1 and Kv3.3. J Neurosci 23:7677-7684.

McMahon A, Fowler SC, Perney TM, Akemann W, Knöpfel T, Joho RH (2004) Allele-dependent changes of olivocerebellar circuit properties in the absence of the voltage-gated potassium channels Kv3.1 and Kv3.3. Eur J Neurosci 19:3317-3327.

Molineux ML, McRory JE, McKay BE, Hamid J, Mehaffey WH, Rehak R,
Snutch TP, Zamponi GW, Turner RW (2006) Specific T-type calcium channel isoforms are associated with distinct burst phenotypes in deep cerebellar nuclear neurons. Proc Natl Acad Sci U S A 103:5555-5560.

Molineux ML, Mehaffey WH, Tadayonnejad R, Anderson D, Tennent AF, Turner RW (2008) Ionic factors governing rebound burst phenotype in rat deep cerebellar neurons. J Neurophysiol 100:2684-2701.

Ozaita A, Martone ME, Ellisman MH, Rudy B (2002) Differential subcellular localization of the two alternatively spliced isoforms of the Kv3.1 potassium channel subunit in brain. J Neurophysiol 88:394-408.

Pugh JR, Raman IM (2006) Potentiation of mossy fiber EPSCs in the cerebellar nuclei by NMDA receptor activation followed by postinhibitory rebound current. Neuron 51:113-123.

Rudy B, McBain CJ (2001) Kv3 channels: voltage-gated $\mathrm{K}^{+}$channels designed for high-frequency repetitive firing. Trends Neurosci 24:517-526.

Rudy B, Chow A, Lau D, Amarillo Y, Ozaita A, Saganich M, Moreno H, Nadal MS, Hernandez-Pineda R, Hernandez-Cruz A, Erisir A, Leonard C, VegaSaenz de Miera E (1999) Contributions of Kv3 channels to neuronal excitability. Ann N Y Acad Sci 868:304-343.

Sekirnjak C, Martone ME, Weiser M, Deerinck T, Bueno E, Rudy B, Ellisman M (1997) Subcellular localization of the $\mathrm{K}^{+}$channel subunit Kv3.1b in selected rat CNS neurons. Brain Res 766:173-187.

Séquier JM, Hunziker W, Andressen C, Celio MR (1990) Calbindin D-28k protein and mRNA localization in the rat brain. Eur J Neurosci 2:1118-1126.

Shakkottai VG, Chou CH, Oddo S, Sailer CA, Knaus HG, Gutman GA, Barish ME, LaFerla FM, Chandy KG (2004) Enhanced neuronal excitability in the absence of neurodegeneration induces cerebellar ataxia. J Clin Invest 113:582-590.

Song P, Yang Y, Barnes-Davies M, Bhattacharjee A, Hamann M, Forsythe ID, Oliver DL, Kaczmarek LK (2005) Acoustic environment determines phosphorylation state of the Kv3.1 potassium channel in auditory neurons. Nat Neurosci 8:1335-1342.

Uusisaari M, Obata K, Knöpfel T (2007) Morphological and electrophysiological properties of GABAergic and non-GABAergic cells in the deep cerebellar nuclei. J Neurophysiol 97:901-911.

Veh RW, Lichtinghagen R, Sewing S, Wunder F, Grumbach IM, Pongs O (1995) Immunohistochemical localization of five members of the Kv1 channel subunits: contrasting subcellular locations and neuron-specific co-localizations in rat brain. Eur J Neurosci 7:2189-2205.

Waters MF, Fee D, Figueroa KP, Nolte D, Müller U, Advincula J, Coon H, Evidente VG, Pulst SM (2005) An autosomal dominant ataxia maps to 19q13: allelic heterogeneity of SCA13 or novel locus? Neurology 65:1111-1113.

Waters MF, Minassian NA, Stevanin G, Figueroa KP, Bannister JP, Nolte D, Mock AF, Evidente VG, Fee DB, Müller U, Dürr A, Brice A, Papazian DM, Pulst SM (2006) Mutations in voltage-gated potassium channel KCNC3 cause degenerative and developmental central nervous system phenotypes. Nat Genet 38:447-451.

Weiser M, Vega-Saenz de Miera E, Kentros C, Moreno H, Franzen L, Hillman D, Baker H, Rudy B (1994) Differential expression of Shaw-related $\mathrm{K}^{+}$ channels in the rat central nervous system. J Neurosci 14:949-972.

Weiser M, Bueno E, Sekirnjak C, Martone ME, Baker H, Hillman D, Chen S, Thornhill W, Ellisman M, Rudy B (1995) The potassium channel subunit KV3.1b is localized to somatic and axonal membranes of specific populations of CNS neurons. J Neurosci 15:4298-4314.

Welsh JP and Harvey JA (1992) The role of the cerebellum in voluntary and reflexive movements: history and current status. In: The cerebellum revisited (Llinas R, Sotelo C, eds), pp 301-334. New York: Springer.

Zhang W, Shin JH, Linden DJ (2004) Persistent changes in the intrinsic excitability of rat deep cerebellar nuclear neurones induced by EPSP or IPSP bursts. J Physiol 561:703-719. 